$13^{\text {th }}$ International Conference on

\title{
Wind Tunnel Experiments and CFD Analysis of Blended Wing Body (BWB) Unmanned Aerial Vehicle (UAV) at Mach 0.1 and Mach 0.3
}

\author{
Wirachman Wisnoe ${ }^{*}$, Rizal Effendy Mohd Nasir ${ }^{* *}$, Wahyu Kuntjoro ${ }^{* * *}$, and Aman Mohd \\ Ihsan Mamat ${ }^{\dagger}$
}

\begin{abstract}
This paper discusses the aerodynamics behavior of a baseline design of a Blended Wing Body (BWB) aircraft developed at MARA University of Technology (UiTM). Two methods of analysis are presented, i.e. Steady-state, three- dimensional Computational Fluid Dynamics (CFD) of the BWB at Mach 0.3 and Wind Tunnel experiments on 1/6 scaled half model of the BWB at Mach 0.1. In both methods of analysis, Lift Coefficient (CL), Drag Coefficient (CD) and Pitching Moment Coefficient (CM) are measured and compared at respective Mach numbers with respect to variation of angle of attack. Pressure contours and Mach number contours are plotted and the turbulence area is predicted, both extracted from CFD analysis. Visualization using mini tuft during wind tunnel tests is also executed to complete the analysis where the stall progression patterns can be clearly observed. The presented BWB UAV design here has achieved an unprecedented capability in terms of sustainability of flight at high angle of attack, low parasite drag coefficient and decent maximum lift coefficient. Some recommendations for future improvement of the BWB are given.
\end{abstract}

Keywords: Aerodynamics, Blended-Wind Body (BWB), Unmanned Aerial Vehicle (UAV), Computational Fluid Dynamics, Wind Tunnel, mini-tuft visualization

\section{Introduction}

Blended Wing Body (BWB) aircraft is a concept where fuselage is merged with wing and tail to become a single entity [1]. BWB is a hybrid of flying-wing aircraft and the conventional aircraft where the body is designed to have a shape of an airfoil and carefully streamlined with the wing to have a desired planform. If the wing in conventional aircraft is the main contributor to the generation of lift, the fuselage of BWB generates lift together with the wing

\footnotetext{
* Associate Professor, Faculty of Mechanical Engineering, Universiti Teknologi MARA, 40450 Shah Alam, MALAYSIA, wira_wisnoe@yahoo.com

** Lecturer, Faculty of Mechanical Engineering, Universiti Teknologi MARA, 40450 Shah Alam, MALAYSIA, fendy117@yahoo.com

*** Professor, Faculty of Mechanical Engineering, Universiti Teknologi MARA, 40450 Shah Alam, MALAYSIA, wkuntjoro@yahoo.com

${ }^{\dagger}$ Lecturer, Faculty of Mechanical Engineering, Universiti Teknologi MARA, 40450 Shah Alam, MALAYSIA, aman_korup@yahoo.com
} 
thus increasing the effective lifting surface area. The streamlined shape between fuselage and wing intersections reduces interference drag, reduces wetted surface area that reduces friction drag while the slow evolution of fuselage-to-wing thickness by careful design may suggest that more volume can be stored inside the BWB aircraft, hence, increases payload and fuel capacity $[1][2]$.

The BWB concept aims at combining the advantages of a flying wing with the loading capabilities of a conventional airliner by creating a wide body in the center of the wing to allow space for passengers and cargo. Especially, for very large transport aircraft, the BWB concept is often claimed to be superior compared to conventional configurations in terms of higher lift-to-drag ratio and consequently less fuel consumption [3].

Since September 2005, UiTM has started a research on BWB of Unmanned Aerial Vehicle (UAV) [4]. The planform of BWB UAV determined during the preliminary can be seen in Fig. 1. Preliminary structural configuration has been analyzed using finite element model [5]. Computational fluid dynamic analysis was also performed on the basic planform at various Mach numbers [6][7] and experimental analysis has been conducted to establish the validation of the CFD simulation [8][9].

This paper will focus on aerodynamic study of preliminary design of BWB planform to be used as a UAV. It consists of Computational Fluid Dynamics (CFD) study of the BWB at 0.1 and 0.3 Mach number, and wind tunnel tests at around 0.1 Mach number. Mach 0.3 represents the cruising phase of the BWB during its flight mission and Mach 0.1 represents the loitering phase (Fig. 2). The aerodynamic characteristics such as lift coefficient, drag coefficient and pitching moment coefficient are obtained and compared. In addition, the CFD visualization of flow and pressure distribution on the surface of the BWB model had been plotted to analyze the flow behavior on the BWB surface at the sub sonic level. On the other hand, visualization using mini tuft is performed in the wind tunnel to observe the quality of flow pattern around the BWB at various angles of attack.

\section{CFD Approach, Methodology and Experimental Setup}

\subsection{CFD Approach, Methodology}

Development of mathematical models involves derivation of geometrical equations for BWB planform. Some parameters such as wing planform area, sweep angle, taper ratio for each section (body, inner wing and outer wing), span and chord for various spanwise locations must be determined for each configuration. These mathematical models are then translated into three dimensional drawing in CATIA where the sizing of preliminary BWB planform configuration is taken as relative to wing span. Fig. 1 shows the three-view drawing of the BWB proposed during its preliminary design.

Second stage involves conversion from three dimensional CATIA CAD model into CFD element in GAMBIT to create the meshing element. Then, the succeeded meshing models were exported to FLUENT for the analysis. The result presented is the simulation for sub sonic flow at Mach number equals to 0.1 and 0.3 corresponding to Reynolds number equals to $4.66 \times 10^{6}$ and $1.4 \times 10^{7}$ respectively. Boundary conditions and airflow are simulated in this stage purposely-executed for two reasons; first is determination of pressure distribution on the surface of the BWB UAV that later on leads to calculations of aerodynamics characteristics of $B W B$ such as $C_{L}, C_{D}$ and $C_{M}$ at various angle of attack, second is the visualization of the 
airflow around the BWB using Post Processing to recognize some critical area with possible vortex reduction in the near future. The analytical of aerodynamics characteristics for various angles of attacks using CFD simulation will be conducted in this final stage.

\subsection{Experimental Setup}

The tests were conducted using UiTM Low Speed Tunnel LST-1 (Fig. 3). This wind tunnel has a test section area of $0.5 \mathrm{~m} \times 0.5 \mathrm{~m} \times 1.25 \mathrm{~m}$. It is a suction type tunnel, equipped with a 3-component balance, capable of measuring lift force, drag force, and pitching moment. Hence, a half model of BWB is used for the tests.

The BWB planform was obtained from [4]. The half model of this BWB-UAV has been manufactured using $\mathrm{CNC}$ machine with a size reduction of 1/6 [10]. Fig. 4 shows the dimension of the half model and Fig. 5 shows the manufactured model.

The tests are conducted at 4 different air speeds, i.e. $25 \mathrm{~m} / \mathrm{s}, 30 \mathrm{~m} / \mathrm{s}, 35 \mathrm{~m} / \mathrm{s}$, and $40 \mathrm{~m} / \mathrm{s}$. The Reynolds number, using base chord length as reference length, is on the order of $10^{5}$, and the Mach number ranges from 0.07 to 0.11 .

\section{Results and Discussion}

\subsection{Lift Coefficient Analysis}

Fig. 6 shows variation of lift coefficient $\left(C_{L}\right)$ for different values of angle of attack $(\alpha)$. For each wind tunnel airspeed, the value of $C_{L}$ increases as the angle of attack is increased until its maximum value at around $\alpha=35^{\circ}$ and decreases afterwards with lower slope. Computational Fluid Dynamics (CFD) results at Mach 0.1 and 0.3 also give the same trend with maximum $C_{L}$ located at $\alpha=39^{\circ}$ and $\alpha=35^{\circ}$ respectively. Table 1 summarizes the maximum values of $C_{L}$ obtained at different measurement.

It is observed that the value of $\mathrm{C}_{\mathrm{Lmax}}$ increases as the air velocity of the wind tunnel is increased. Hence, the $\mathrm{C}_{\mathrm{Lmax}}$ increases with the increase of Reynolds number (Fig. 7). This explains the difference of values of $\mathrm{C}_{\mathrm{Lmax}}$ between the experiments and the CFD.

Table 1. Maximum values of $C_{L}$ for different airspeeds (or Mach numbers)

\begin{tabular}{c|c|c|c}
\hline \hline $\mathbf{v ~ ( m / s )}$ & $\mathbf{M}$ & $\boldsymbol{\alpha}(\mathbf{d e g})$ & $\mathbf{C}_{\mathbf{L}} \mathbf{m a x}$ \\
\hline & & & \\
\hline 25 & 0.072 & 34 & 0.649 \\
\hline 30 & 0.086 & 35 & 0.664 \\
\hline 35 & 0.101 & 34 & 0.687 \\
\hline 40 & 0.115 & 34.5 & 0.749 \\
\hline & & & \\
\hline CFD (M=0.1) & 0.1 & 39 & 1.043 \\
\hline CFD (M=0.3) & 0.3 & 35 & 1.031 \\
\hline \hline
\end{tabular}


The experimental curves presented in Fig. 6 also show clearly a deflection at around $\alpha=8^{\circ}$. The visualization reveals the flow separation around the wing area around this angle of attack that results in reduction in lifting surface area (Fig. 8 and Fig. 9). The deflection of curves is also observed in CFD results, although it is not very clear.

Fig. 8 to Fig. 10 show visualization using mini tuft, taken at wind tunnel airspeed of $35 \mathrm{~m} / \mathrm{s}$. In Fig. 8, it can be seen that the flow is still attached to the overall surface at $\alpha=7^{\circ}$. However, in Fig. 9, at $\alpha=8^{\circ}$, the flow has almost completely separated from the wing, except around the wing tip. This means that, above this angle of attack, only the body generates the lift. The body will continue generating lift until $\mathrm{C}_{\mathrm{Lmax}}$ and from there; separation starts to occur on the body part. The separation does not occur completely, as there is always part of the body where the flow is still attached. Fig. 10 shows the flow pattern around the body at $\alpha=42^{\circ}$.

\subsection{Drag Coefficient Analysis}

Fig. 11 shows variation of drag coefficient $\left(C_{D}\right)$ versus angle of attack $(\alpha)$ taken at different air speeds and Mach numbers. It is observed that the variation of drag coefficient is very slow and almost constant at low angle of attacks (below $8^{\circ}$ ). In that range of $\alpha, C_{D}$ is small, below 0.03 for both experiments and CFD. As explained in the previous section, at low angle of attack, the air flow is still attached to the body and the wing.

Above $8^{\circ}, C_{D}$ grows at higher rate as $\alpha$ is increased. Within this range, the wing is already in stall condition. Around $35^{\circ}$, a slight deflection occurs on wind tunnel experiment curves. This is where the lift coefficient reaches its maximum value. This deflection is not clearly seen on the CFD curves. Beyond this angle of attack, the drag coefficient continues to increase with almost the same slope as between $8^{\circ}$ and $34^{\circ}$, and it is getting slower when $\alpha$ approaches $90^{\circ}$.

From the overall curves, it is observed that higher airspeeds (or higher Reynolds number) produce higher drag coefficients.

\subsection{Pitching Moment Coefficient Analysis}

The curve of pitching moment coefficient $\left(C_{M}\right)$ versus angle of attack $(\alpha)$ is presented in Fig. 12. The calculation of $C_{M}$ is performed with respect to the nose of the aircraft. Here, it is seen that, for all airspeeds, the moment coefficient decreases as $\alpha$ is increased. It is also noticed (on experimental curves) a slight deflection at around $8^{\circ}$ which corresponds to the flow separation around the wing. Another deflection occurs at around $34^{\circ}$ which corresponds to the maximum of lift coefficient. It is observed that the curves of $\mathrm{C}_{\mathrm{M}}$ are almost identical for $\alpha$ below $34^{\circ}$ for the four wind tunnel airspeeds. In other word, from experimental results, the pitching moment coefficient measured at the nose of the aircraft is independent of airspeed at angles of attack below the angle of attack corresponding to maximum lift. The CFD results give slightly higher values of $\mathrm{C}_{\mathrm{M}}$, but also independent of the Mach number.

\subsection{Lift Coefficient versus Drag Coefficient Analysis}

The drag polar $\left(C_{L}\right.$ versus $\left.C_{D}\right)$ curve can be seen in Fig. 13. From experimental curves, the value of drag coefficients at zero lift $\left(\mathrm{C}_{\mathrm{Do}}\right)$ is around 0.03 . The $\mathrm{CFD}$ results give $\mathrm{C}_{\mathrm{Do}}$ lower than 0.02. This is the minimum drag coefficient that the BWB has without producing any lift. From the curves, it can be seen that when the drag coefficient increases, the lift coefficient increases until its maximum value $\mathrm{C}_{\mathrm{Lmax}}$ and then decreases. The polar is bigger when the airspeed is higher. 


\subsection{Lift-to-Drag Ratio Analysis}

Fig. 14 shows the curve of lift-to-drag ratio (L/D) as a function of angle of attack $(\alpha)$. It is noticed that, for experiments curves, the lift-to-drag ratio increase from a minimum value of 7.65 at $\alpha=-7^{\circ}$ to its maximum value of 7.27 at $\alpha=6^{\circ}$. The CFD gives the maximum value of $\mathrm{L} / \mathrm{D}=11.07$ (for Mach 0.1) and $\mathrm{L} / \mathrm{D}=12.24$ (for Mach 0.3) both at $\alpha=3^{\circ}$. These angles of attack ( $\alpha=6^{\circ}$ from experiments and $\alpha=3^{\circ}$ from CFD analysis) indicate the optimum flight configuration of the BWB.

These lift-to drag ratios are considered low. Cranfield University with its BWB design manages to have maximum lift-to-drag ratio of 14 [1].

\subsection{Pressure Coefficient Contours}

The pressure coefficients contours at the upper surface of the BWB are shown in Fig. 15 and Fig. 16. They are obtained from CFD analysis for 0.3 Mach number. It is observed that when the angles of attack, $\alpha$ increase, the upper surface will create a lower pressure coefficient, $C_{P}$. In Fig. 15 the high-intensity blue area located on the upper surface suggests high lift (negative pressure/suction) is generated (low $\alpha$ with $7.4 \%$ force directed backward creating drag). In high angle of attack (Fig. 16), the BWB-UAV is still capable of generating lift, however about $1 / 3$ of the total force is directed backward (drag).

\subsection{Mach Number Contours and Pathlines}

Mach number contours of upper and lower surfaces form CFD analysis at 0.3 Mach number are shown in Fig. 17 and Fig. 18. Increasing angles of attack will cause the Mach number on upper surface to increase while simultaneously decreasing on the lower surface. This results in the lift coefficient increasing when angle of attack increases. As angle of attack increases more, the flow will eventually separate from the surface. Separation starts from the wing root and spreads towards the body and wing area. Figure 6 shows flow over the wings at the stall angle of $35^{\circ}$. Although the wing does not provide lift at this $\alpha$, effective flow occurs on the center body resulting in some lift being generated by the high swept leading edge vortex on the body (similar to delta wing).

\section{Conclusions}

This paper reports the aerodynamic performance of UiTM BWB-UAV intended to be capable for low subsonic operation. The 3-D model generated by CATIA became the basis of the CFD model for predicting the pressure and flow distributions of the airplane, which subsequently developed to be the aerodynamic load. Fluent software was employed in the CFD analysis. Half model of the BWB has been used for wind tunnel tests.

Lift, drag, and pitching moment obtained from wind tunnel experiments have been studied, analyzed and compared with the CFD results. The experiments have been conducted around Mach 0.1 and the CFD analysis at Mach 0.1 and 0.3. These Mach numbers represent the loitering and the cruising phase of the mission profile.

From the $\mathrm{C}_{\mathrm{L}}$ curves obtained from both CFD and wind tunnel experiments, coupled with visualization using mini tuft, it can be concluded that this type of BWB can fly at very high angle of attack. The maximum lift is given for $\alpha$ around $34^{\circ}-39^{\circ}$. This is due to the delta wing shape for the proposed BWB model. However, the wing is already in stall condition at $\alpha$ 
around $8^{\circ}$, which is considered to be low. This means that the main contributor of the lift is the aircraft body.

The ineffectiveness of the wing implies that the aileron control will not be effective; hence lateral control must be addressed in future research. The maximum lift-to-drag ratio is obtained at $\alpha=6^{\circ}$ (from wind tunnel experiments) and $\alpha=3^{\circ}$ (from CFD analysis). This represents the optimum flight configuration with optimum fuel consumption.

The values obtained from experiments are overall lower than those from CFD. One of the reasons is that the Reynolds number used in this experimental study is much smaller than the CFD.

It is recommended to improve the wing to delay the flow separation. It can be done by changing the airfoil of the wing with more appropriate airfoil for low speed, and/or by increasing the surface area of the wing to generate more lift, and/or by twisting the wing to delay the separation.

Further experiments should also be conducted to study other aerodynamics parameters, including yaw and roll, and also with higher Reynolds number.

\section{References}

[1] Qin, N., Vavalle, A., Le Moigne, A., Laban, M., Hackett, K., and Weinnerfelt, P., "Aerodynamic Considerations of Blended Wing Body Aircraft", Progress in Aerospace Science, 2004, pp. 321-343

[2] Engels, H., Becker, W., and Morris, A., "Implementation of a Multi-Level Methodology Within the E-Design of A Blended Wing Body", Aerospace Science and Technology, 2004, pp. 145-153

[3] Liebeck, R.H., Page, M.A., and Rawdon, B.K., "Blended-Wing-Body Subsonic Commercial Transport", AIAA Paper 98-0438, 1998

[4] Mamat, A. M. I., Mohd Nasir, R. E., and Ngah, Z., "Aerodynamics Of Blended Wing Body (BWB) Unmanned Aerial Vehicle Using Computational Fluid Dynamics (CFD)", UiTM Malaysia - IRDC Research No. 600-IRDC/ST 5/3/1025, 2005

[5] Kuntjoro, W., Mohd Nasir, R. E., Wisnoe, W., Mamat, A. M. I., and Abdulah, M. R., "Computer Aided Design and Engineering of Blended Wing Body UAV", Proceedings of Aircraft Structural Design Conference, Liverpool, UK, 14-16 October 2008

[6] Mamat, A. M. I., Mohd Nasir, R. E., Kuntjoro, W., Wisnoe, W., Ngah, Z., and Ramly R., "Aerodynamics of Blended Wing Body (BWB) Unmanned Aerial Vehicle (UAV) Using Computational Fluid Dynamycs (CFD)", Journal of Mechanical Engineering, Institut Teknologi MARA, Vol. 5 No. 2, October 2008, pp. 15-26

[7] Mohd Nasir, R. E., Mamat, A. M. I., Ngah, Z., Kuntjoro, W., Wisnoe, W., and Ramly R., "Aerodynamics Of Blended Wing Body (BWB) Unmanned Aerial Vehicle (UAV) Using Computational Fluid Dynamics (CFD)", Proceedings of International Conference on Mechanical and Manufacturing Engineering 2008 (ICME 2008), Universiti Tun Hussein Onn Malaysia (UTHM), Johor Bahru, Malaysia, 21-23 May 2008

[8] Wisnoe, W., Mamat, A. M. I., Mohd Nasir, R. E., and Kuntjoro, W., "Aerodynamics Prediction of Blended Wing Body (BWB) of Unmanned Aerial Vehicle (UAV) Using Wind Tunnel Experimental Approach", UiTM Malaysia - FRGS Research No. 600IRDC/ST/FRGS 5/3/1177 
[9] Wisnoe, W., Mamat, A. M. I., Mohd Nasir, R. E., Kuntjoro, W., and Ramly, R., "Wind Tunnel Experiments Of Blended Wing Body (BWB) Unmanned Aerial Vehicle (UAV) At Loitering Phase", Proceedings of International Conference on Mechanical and Manufacturing Engineering 2008 (ICME 2008), Universiti Tun Hussein Onn Malaysia (UTHM), Johor Bahru, Malaysia, 21-23 May 2008

[10] Mohamad Zulkifli, A. R., "Blended Wing Body (BWB) Unmanned Aerial Vehicle (UAV) Model Manufacturing Using CNC Machine", B.Eng. Thesis, Universiti Teknologi MARA Malaysia, 2007 

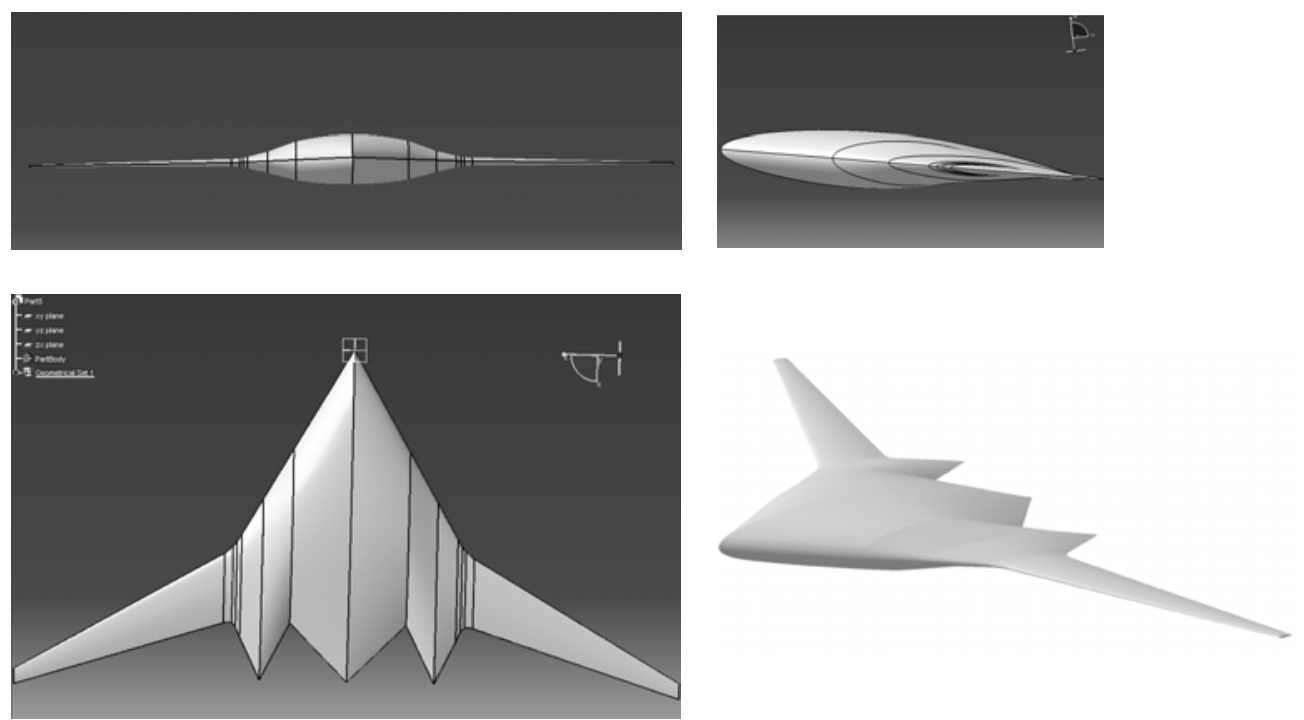

Fig. 1. UiTM BWB-UAV

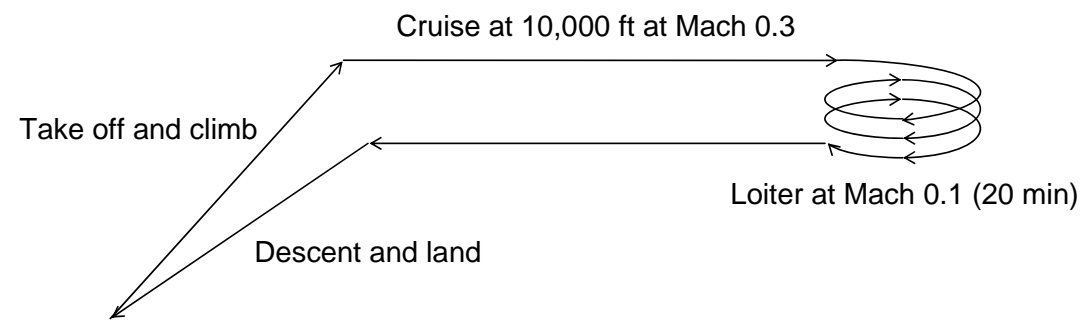

Fig. 2. UiTM BWB Mission Profile

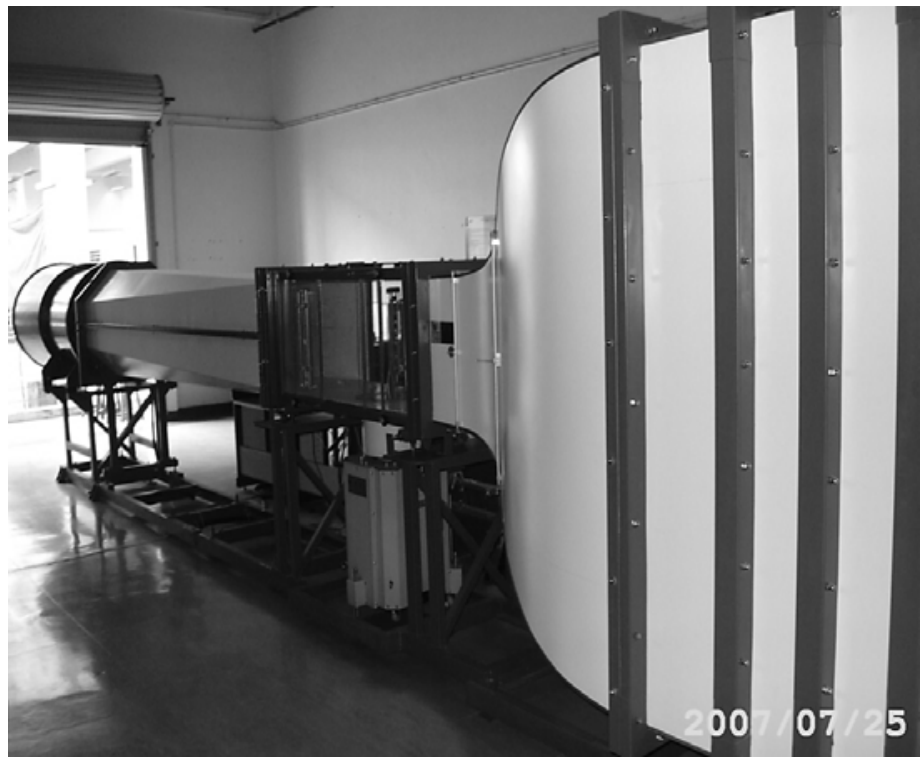

Fig. 3. UiTM Low Speed Wind Tunnel 


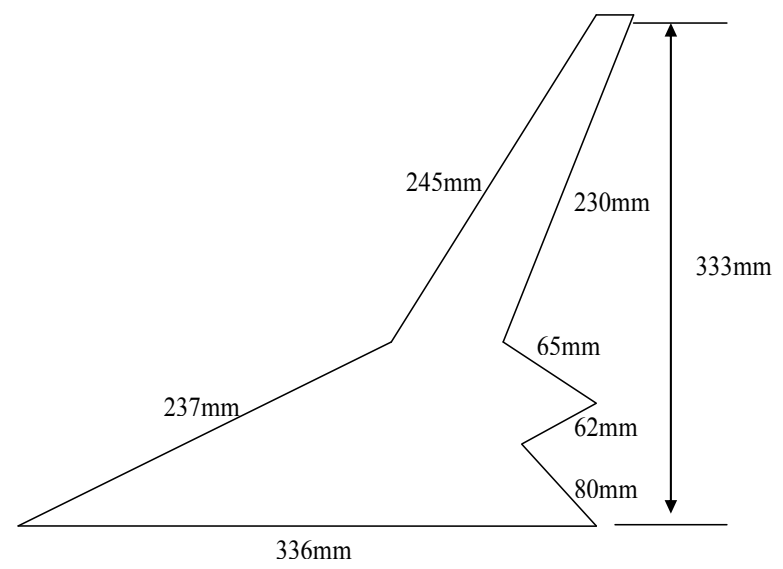

Fig. 4. Dimension of BWB half model

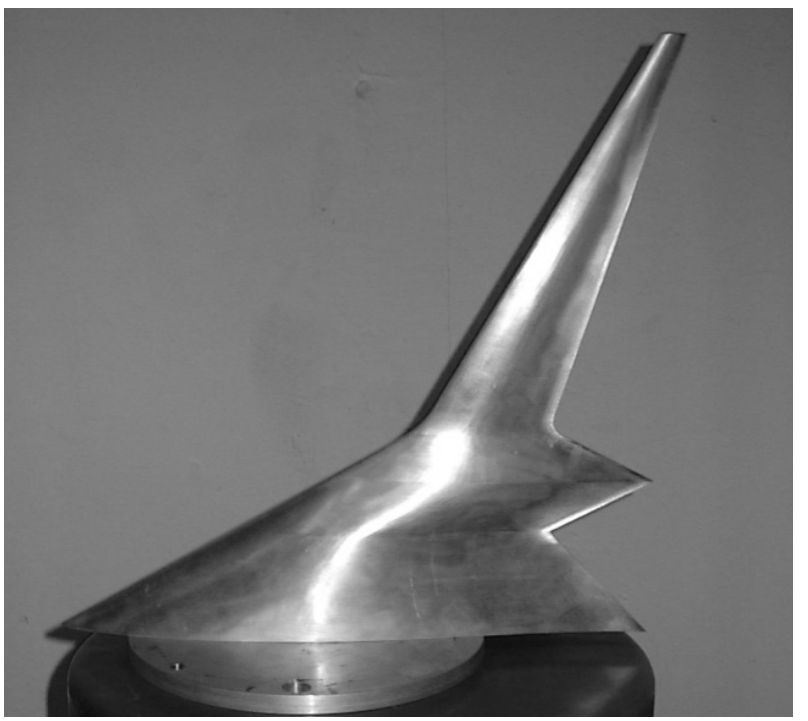

Fig. 5. UiTM BWB-UAV Half Model 


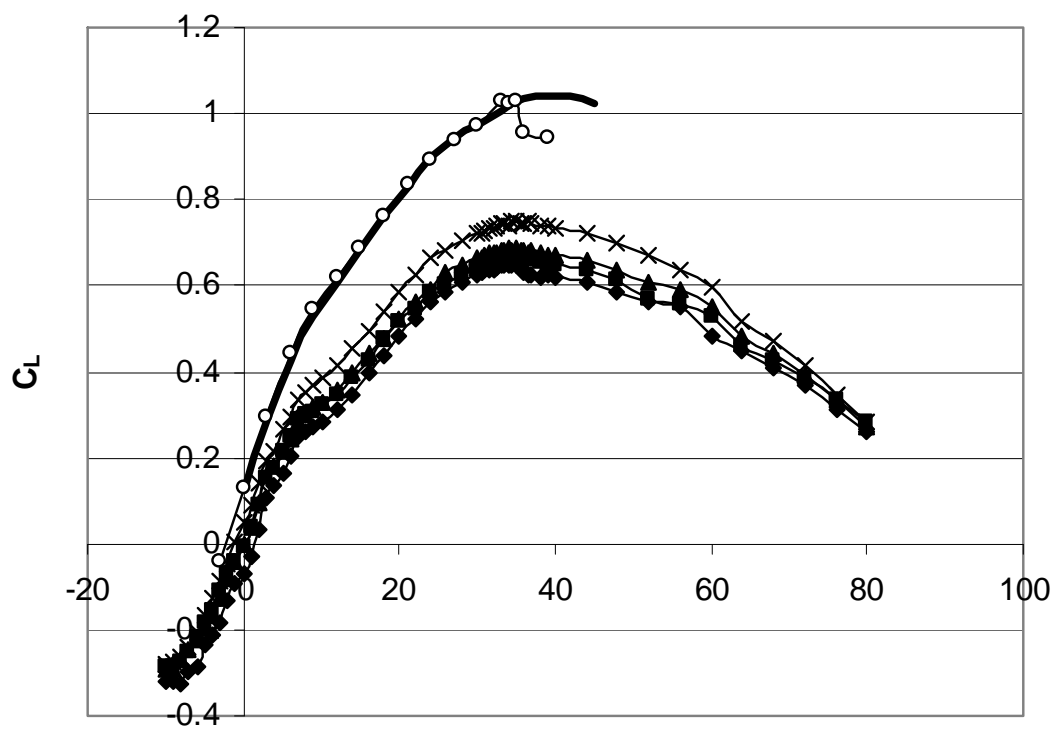

Alpha (deg)

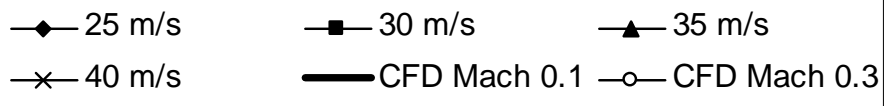

Fig. 6. $C_{L}$ versus $\alpha$

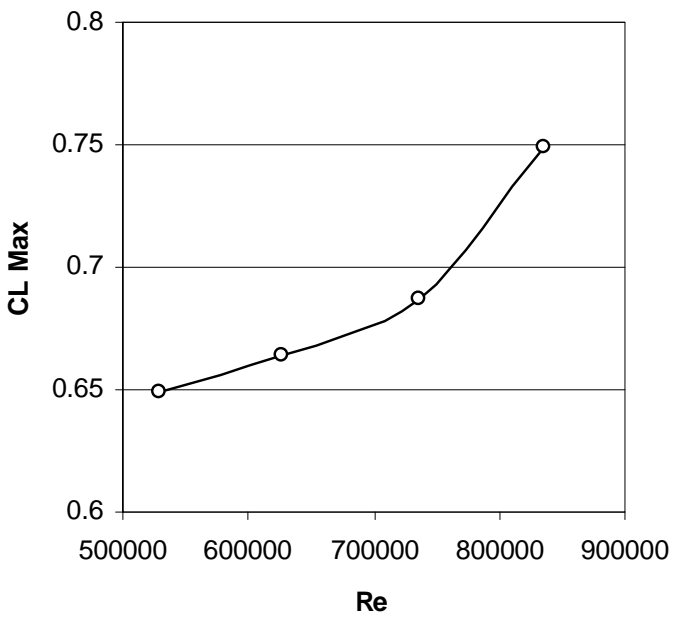

Fig. 7. $C_{\text {Lmax }}$ versus Reynolds number for wind tunnel experiments 


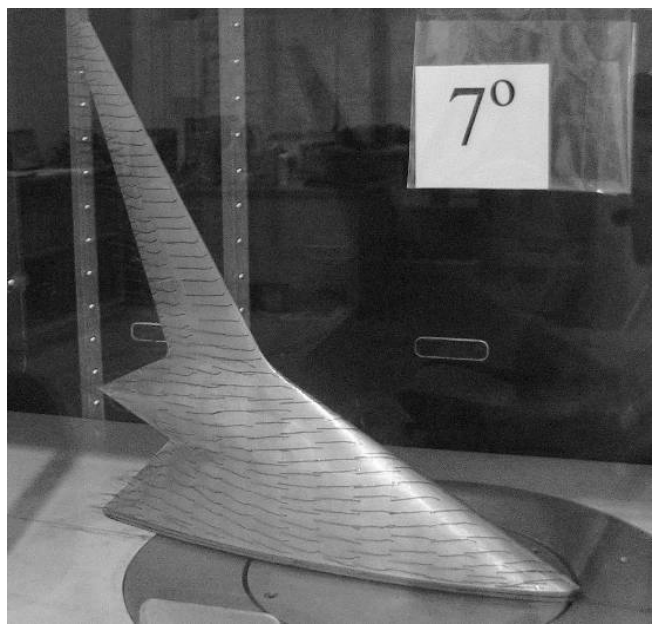

Fig. 8. Visualization at $\alpha=7^{\circ}$

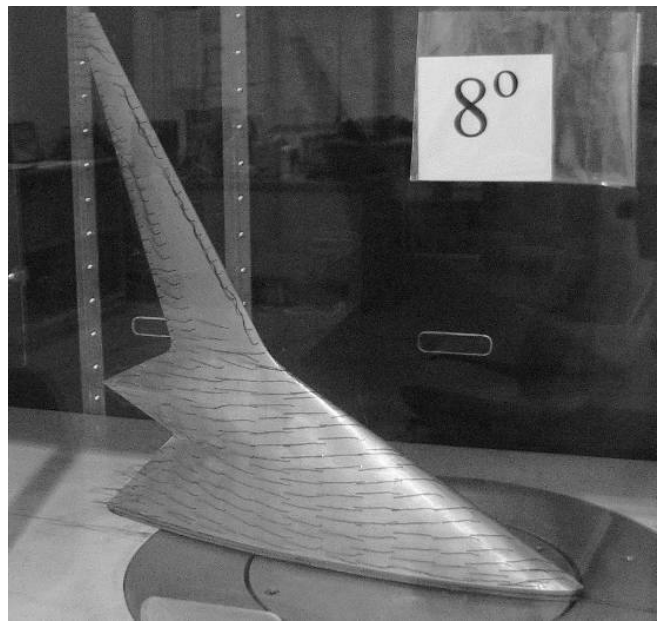

Fig. 9. Visualization at $\alpha=8^{\circ}$

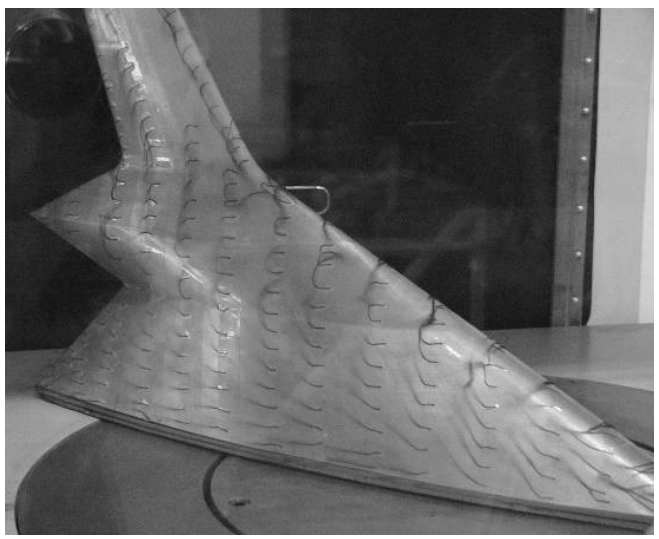

Fig. 10. Visualization at $\alpha=42^{\circ}$ 


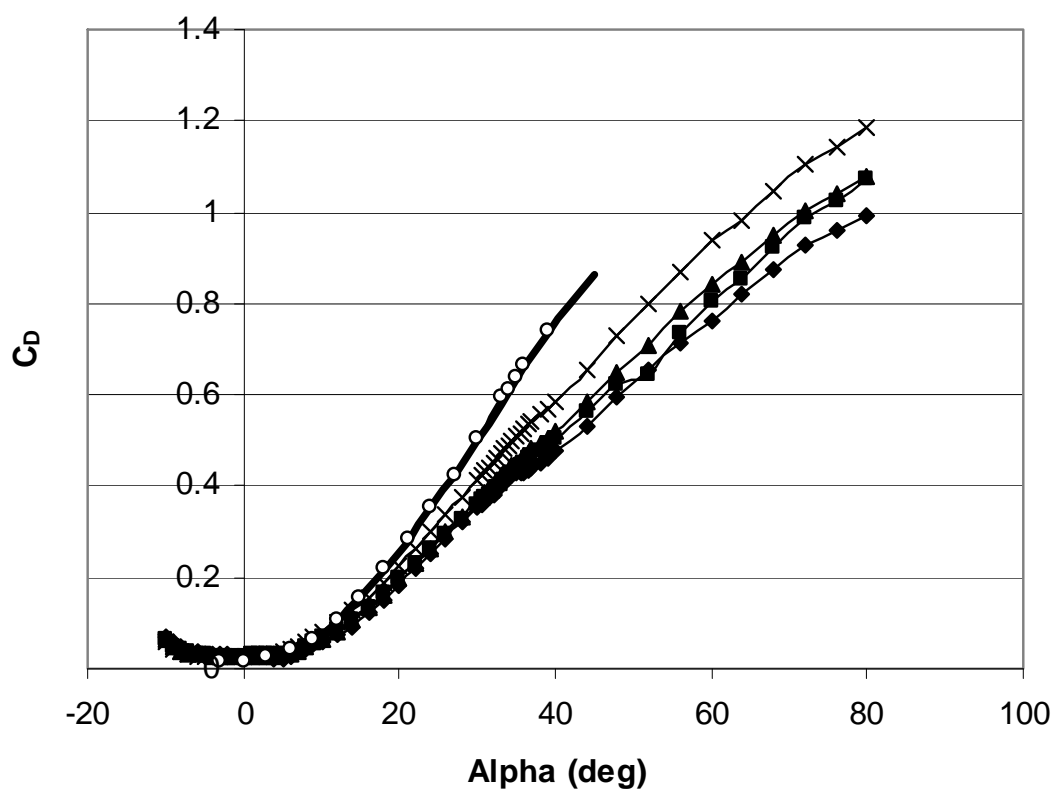

$$
\begin{array}{ll}
\longrightarrow 25 \mathrm{~m} / \mathrm{s} & \rightarrow 30 \mathrm{~m} / \mathrm{s} \quad \longrightarrow 35 \mathrm{~m} / \mathrm{s} \\
\hdashline-40 \mathrm{~m} / \mathrm{s} & \longrightarrow \text { CFD Mach } 0.1 \multimap-\text { CFD Mach } 0.3
\end{array}
$$

Fig. 11. $C_{D}$ versus $\alpha$

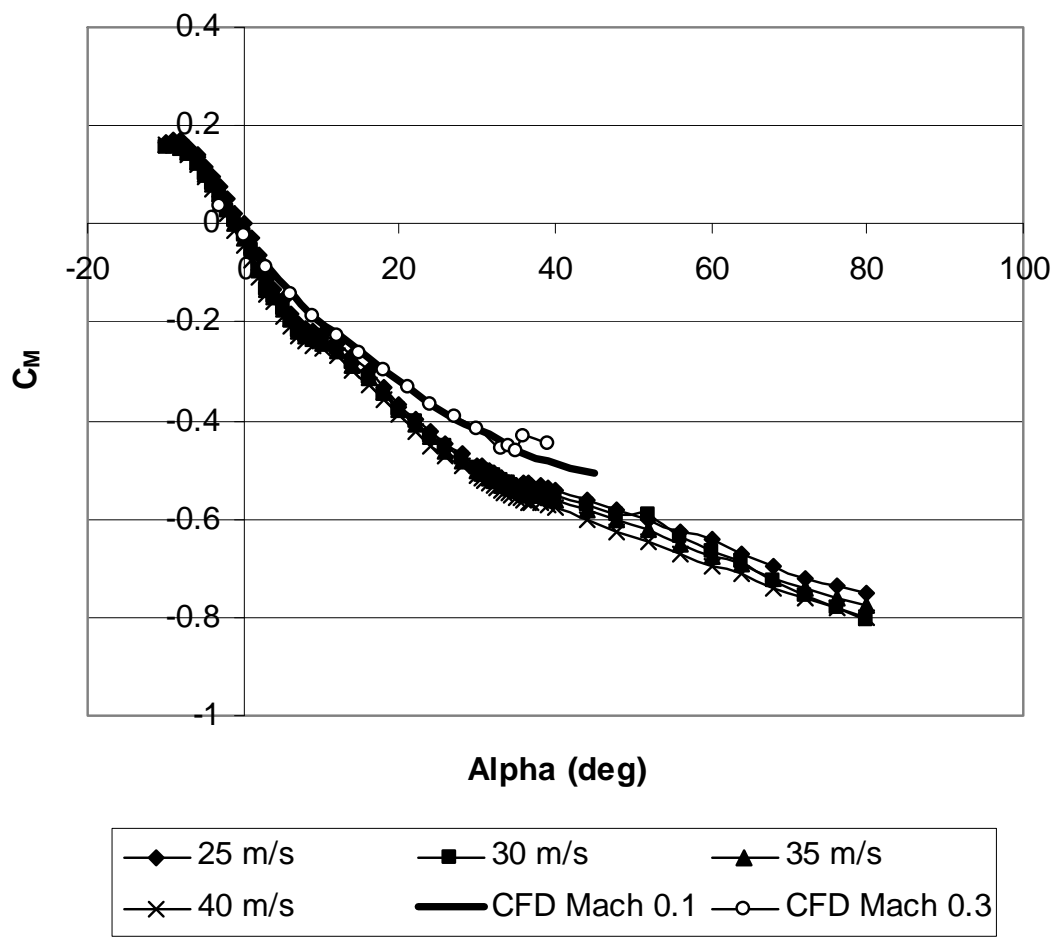

Fig. 12. $C_{M}$ versus $\alpha$ 


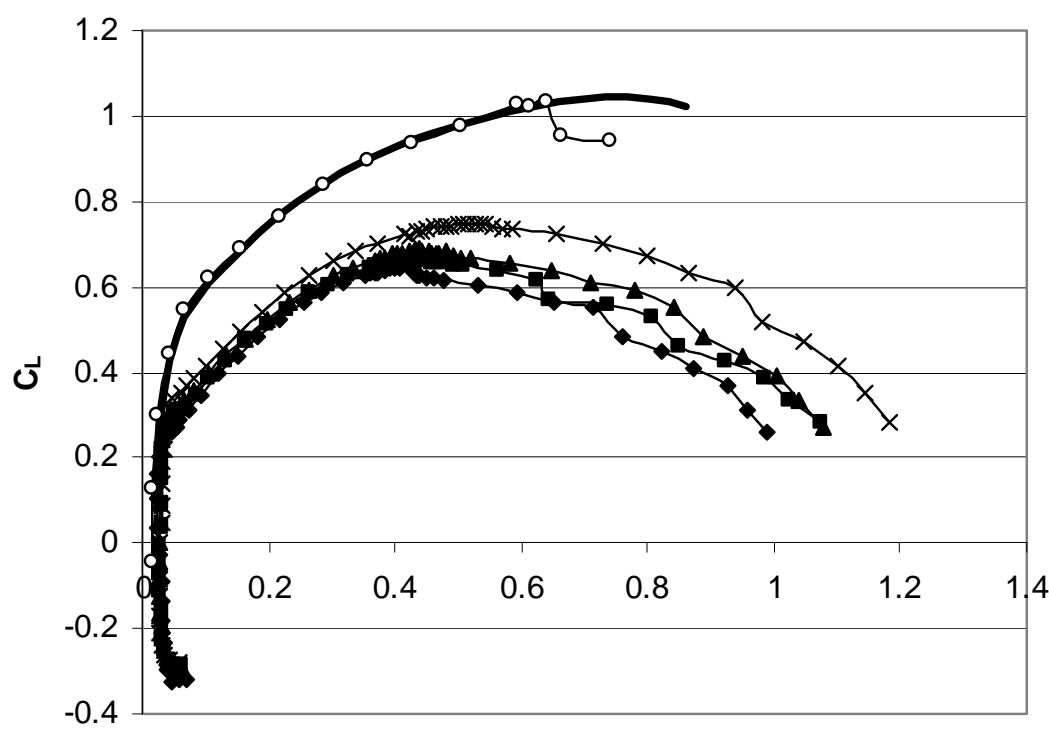

$C_{D}$

$\begin{array}{ll}\longrightarrow-25 \mathrm{~m} / \mathrm{s} & \longrightarrow 30 \mathrm{~m} / \mathrm{s} \quad \longrightarrow 35 \mathrm{~m} / \mathrm{s} \\ \longrightarrow 40 \mathrm{~m} / \mathrm{s} & \longrightarrow \text { CFD Mach } 0.1 \multimap \text { CFD Mach } 0.3\end{array}$

Fig. 13. CL versus CD

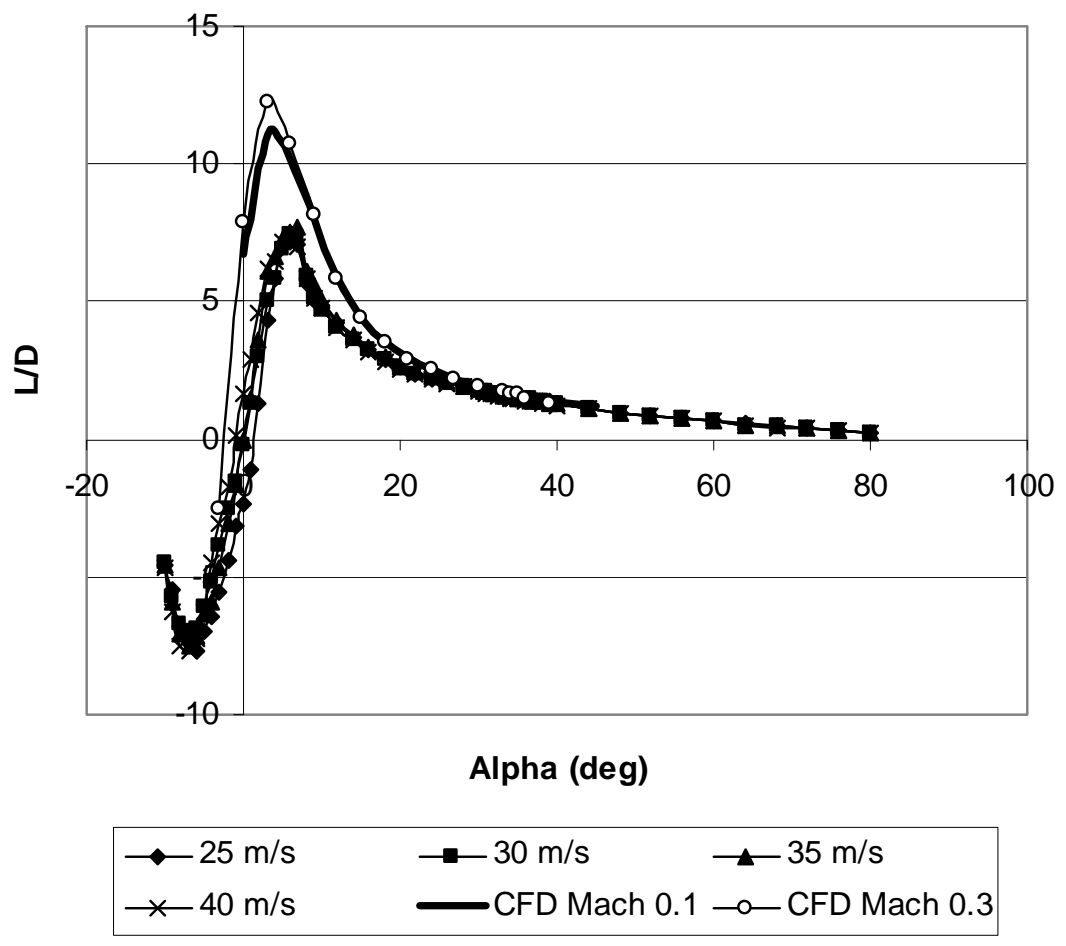

Fig. 14. L/D versus $\alpha$ 


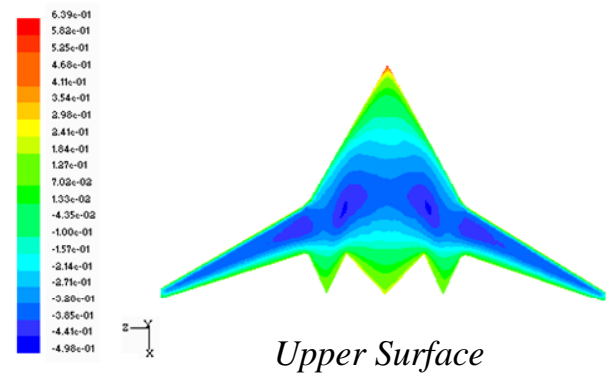

Fig. 15. Pressure coefficient contours at $\alpha=0^{\circ}, M=0.3$

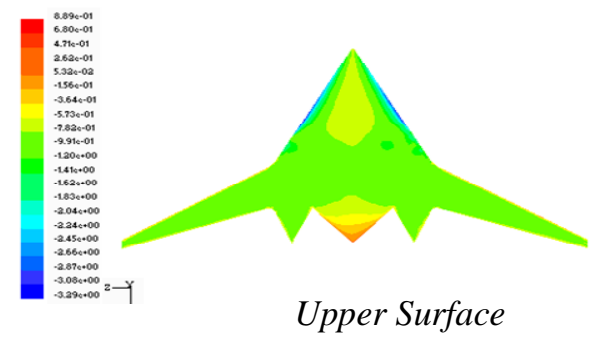

Fig. 16. Pressure coefficient contours at $\alpha=35^{\circ}, M=0.3$
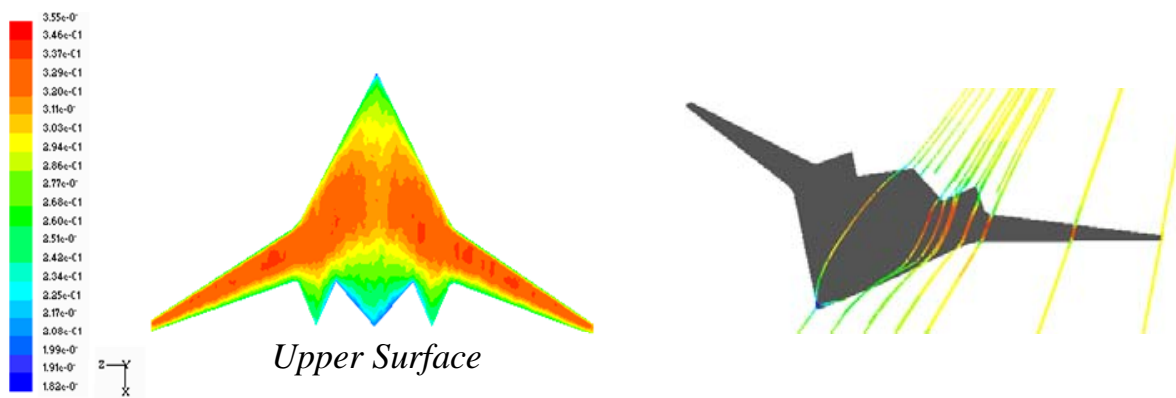

Fig. 17. Mach number contour and Pathlines contours at $\alpha=0^{\circ}, M=0.3$ 


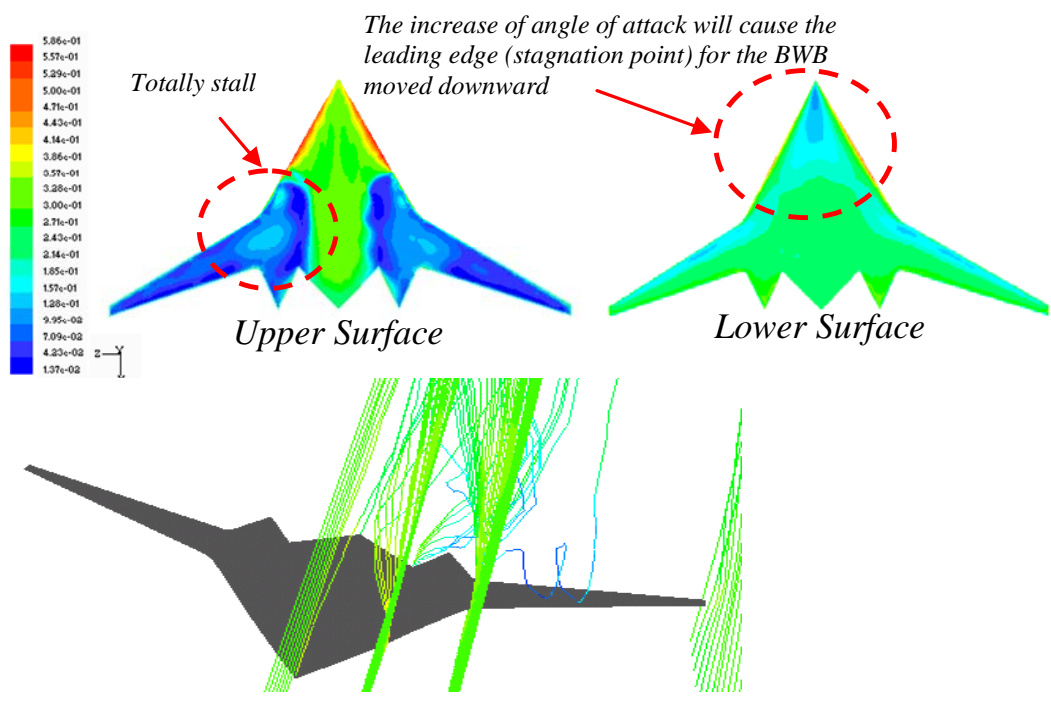

Fig. 18. Mach number contours and Pathlines at $\alpha=35^{\circ}$ for upper and lower surfaces, $M=0.3$ 